\title{
Refining Petroleum
}

Last month's Historical Note described crude oil and the techniques used over the centuries to extract it from the ground. An average sample of crude oil is a greasyfeeling, greenish-brown liquid with a strong odor. The crude can be thick and tarry, such as in oil sands, or light and bubbly if it contains a high percentage of dissolved natural gas. Crude oil serves as the raw material for some 3000 different products-but first the petroleum must be refined.

Near a producing oil field, crude petroleum is stored in large tanks until it can be shipped by tankers or over pipelines to the nearest refinery. Preliminary small-scale tests on samples of the crude initially determine the rough percentages of gasoline, kerosene, fuel oil, lubricating oil, and wax that can be recovered from it.

Petroleum refining techniques have been developed to separate out the useful components of crude oil. Any particular sample contains a large number of separate hydrocarbon compounds, many of them in very small percentages. Chemists at the National Bureau of Standards (now the National Institutes of Standards and Technology) began work in 1927 to determine all the constituents of a typical gasoline obtained from one part of the central United States; they eventually identified over 60 different hydrocarbons in a single sample, ranging from methane $\left(\mathrm{CH}_{4}\right.$, which boils at $-161^{\circ} \mathrm{C}$ ) to mesitylene (an aromatic hydrocarbon with a boiling point of $176^{\circ} \mathrm{C}$ ).

In the mid-19th century, James Young in England found a way to obtain oil from coal as a substitute for expensive whale oil; shortly afterward, chemist Abraham Gesner developed an improved coal oil specifically for use in lamps. By 1859-the same year Colonel E.A. Drake in Pennsylvania struck the first commercial oil wellsome 60 small coal-oil refineries had been established in the United States. Two years later, the first refinery designed specifically to refine petroleum began operation.

Early refineries used a process called batch distillation, in which the crude oil was placed in a heated cylinder called a cheesebox still, or a horizontal cylindrical still. When the vapor temperature of the heated crude reached about $38^{\circ} \mathrm{C}$, the light hydrocarbons vaporized and then condensed in a pipe coil immersed in a water tank. These first products had little value in the late 19th century and were often discarded, though some were sold as "petroleum ether" to be used as a solvent.
Next to be distilled from the heated crude was the gasoline fraction, also considered economically unimportant at the time. In fact, the first runnings of gasoline were dumped into Pennsylvania rivers, where they occasionally caught fire and caused enormous pollution problems.

When the crude temperature rose to $177^{\circ} \mathrm{C}$, an operator tested the specific gravity of the condensate. If it had reached a chosen value, the output stream was shunted to a new tank. Up to about $260^{\circ} \mathrm{C}$, the condensate was considered the kerosene fraction-at the time the most economically important portion because of its broad use in lighting.

When specific gravity tests suggested that the kerosene fraction had boiled off, the output was diverted to yet another tank, where light fuel oils were distilled, followed by successively heavier fractions of waxes, lubricating oils, and asphalts.

These early batch distillation processes were inefficient, providing no sharp separations of distillate products. Gasoline contained kerosene; kerosene contained heavier fuel oils and lighter gasolines. This latter problem proved particularly dangerous, since residual gasoline in kerosene fuel frequently made kerosene lamps explode. While redistillation of primary crude-oil fractions alleviated these problems somewhat, fractionating columns have become the most widely used solutions.

Giant fractionating towers, steel cylinders about $37 \mathrm{~m}$ high, are filled with layers of horizontal trays. The fractionating tower has a temperature gradient, hottest at the bottom near the furnace and cooler at the top. Vapors from below rise through oneway valves called "bubble caps" in the trays; as the vapors rise up the tower, the heavier compounds condense out at lower levels while lighter low-boiling-point compounds continue to rise. Each tray fills with liquid with a boiling point equal to that level in the tower.

Gasoline currently accounts for $46 \%$ of the total volume of refined petroleum in the United States. Fuel oils, refined primarily for heating purposes and for powering large engines, account for roughly $30 \%$. Diesel fuel, less highly refined than gasoline, is used in trucks, ships, locomotives, and automobiles with specially designed engines, and accounts for about $10 \%$ of refinery output. Another $8 \%$ of the refined petroleum is high-performance aviation fuel; this percentage has increased greatly since the 1950 s when piston-engine planes gave way to larger jet aircraft.

Kerosene, the fraction in greatest demand at the turn of the century, now plays a very small role, primarily as a home cooking and heating fuel, and as a component in certain jet fuels; only about $1 \%$ of refined petroleum is made into kerosene. Another $1 \%$ is refined into lubricants, $3 \%$ into asphalt, and $1 \%$ into petrochemicals, which are raw materials for thousands of products such as plastics, paints, fertilizers, solvents, cosmetics, and drugs.

The first gasoline service station was established in 1907. The introduction of the automobile caused a tremendous demand on refineries to increase the gasoline fractions refined from petroleum.

Unfortunately, crude oil does not contain hydrocarbons in the percentages we find most commercially desirable, so refiners have developed techniques to boost certain fractions. These are called conversion processes, which change the less valuable fractions into those in greatest demand.

The first conversion process, thermal cracking, was initially used in 1913 in the Whiting refinery of the Standard Oil Company of Indiana. When heated to high temperatures at high pressures, the leftover heavier fractions (longer hydrocarbon chains) of crude oil begin to break down; shorter molecules split off and can be recaptured as gasolines or aviation-grade fuels. Through thermal cracking, Whiting was able to obtain about $35 \mathrm{vol} \%$ gasoline from its residual heavy fractions.

A similar process, catalytic cracking, was introduced by Eugene Jules Houdry in the 1930 s to use refractory-clay catalysts in petroleum refining. In 1936, two American oil companies-Sun and Socony Mobiladopted the Houdry process to improve the yield from cracking, and also to obtain superior-grade gasolines. During World War II, gasoline cracked in this process formed the majority of aviation fuel.

Other conversion processes take different approaches. For instance, in polymerization the smaller light fractions are combined into larger hydrocarbons such as gasoline. Chemical processes such as alkylation, hydrogenation, and reforming were developed and extensively used during World War II.

Clever applications of these techniques have helped increase the desirable output from a limited resource. For example, new materials such as aerogels are being used to convert methane molecules into longerchain hydrocarbons. As petroleum becomes more precious, we cannot afford to waste any portion of refinery output.

KEVIN J. ANDERSON 